\title{
Striatal Dopaminergic and Serotonergic Markers in Human Heroin Users
}

\author{
Stephen J. Kish, Ph.D., Kathryn S. Kalasinsky, Ph.D., Peter Derkach, M.D., \\ Gregory A. Schmunk, M.D., Mark Guttman, M.D., Lee Ang, M.D., Vernard Adams, M.D., \\ Yoshiaki Furukawa, M.D., Ph.D., and John W. Haycock, Ph.D.
}

To establish whether chronic opiate exposure might impair brain dopaminergic or serotonergic function in humans, we assessed biochemical indices of monoaminergic neurotransmitter activity and integrity in post mortem striatum of nine chronic heroin users and 14 control subjects. Striatal levels of the vesicular monoamine transporter were normal, suggesting that the density of dopamine nerve terminals is not reduced in heroin users. In nucleus accumbens, levels of tyrosine hydroxylase protein $(-25 \%)$ and those of the dopamine metabolite homovanillic acid $(-33 \%)$ were reduced significantly together with a trend for decreased dopamine (-32\%) concentration. These changes could reflect either a compensatory downregulation of dopamine biosynthesis in response to prolonged dopaminergic stimulation caused by heroin, or reduced axoplasmic transport of tyrosine hydroxylase. Striatal levels of serotonin were either normal or elevated whereas concentrations of the serotonin metabolite 5-hydroxyindoleacetic acid were decreased by 27-38\%. Our data suggest that chronic heroin exposure might produce a modest reduction in dopaminergic and serotonergic activity that could affect motivational state and impulse control, respectively.

[Neuropsychopharmacology 24:561-567, 2001] (C) 2001 American College of Neuropsychopharmacology. Published by Elsevier Science Inc.
KEY WORDS: Heroin; Opiate; Dopamine; Serotonin; Dopamine transporter; Vesicular monoamine transporter; Extracellular signal-regulated kinase

From the Human Neurochemical Pathology Laboratory, Centre for Addiction and Mental Health, Toronto, Ontario, Canada (SJK, PD, MG, YF), Division of Forensic Toxicology, Office of the Armed Forces Medical Examiner, Armed Forces Institute of Pathology, Washington, DC (KSK), Santa Clara County Medical Examiner-Coroner San Jose, CA and Stanford University, Palo Alto CA (GAS), Department of Pathology (Neuropathology), Sunnybrook Hospital, Toronto, Canada (LA), Office of the Hillsborough County Medical Examiner, Tampa, FL (VA), and Department of Biochemistry and Molecular Biology, Louisiana State University Medical Center, New Orleans, LA (JWH).

Address correspondence to: Stephen J. Kish, Ph.D., Human Neurochemical Pathology Laboratory, Centre for Addiction and Mental Health, 250 College Street, Toronto, Ontario, Canada M5T 1R8, Tel.: 416-535-8501, ext. 6256; Fax: 416-979-6871; e-mail: Stephen_Kish@ CAMH.net

Received February 8, 2000; revised September 19, 2000; accepted September 21, 2000.
An important feature of psychostimulant and opiate drugs of abuse is their ability, upon acute administration, to activate brain dopaminergic neurons as evidenced by increased striatal synaptic concentrations of dopamine (DiChiara 1995). Chronic dopaminergic overactivity caused by drugs of abuse leads to a variety of compensatory changes that could influence behavior of the drug user. Synaptic levels of dopamine are decreased in experimental animals withdrawn from chronic psychostimulants (cf. DiChiara 1995) whereas striatal tissue dopamine levels are reduced in human chronic psychostimulant users: moderately for methamphetamine users (Wilson et al. 1996a) or slightly for cocaine users (Wilson et al. 1996b). These changes could explain the dysphoric anhedonic motivational state during withdrawal to psychostimulant drugs. Both experimental animals and humans (cf. Wilson et al. 1996a,b) exposed to psychostimulants also demonstrate altered striatal levels of the dopamine transporter (DAT), a 
component of the dopamine nerve terminal critically involved in regulation of synaptic dopamine levels.

Relatively less attention has been focused on longterm effects of opiate drugs of abuse on the dopamine system. In fact, it has been assumed that opiates do not produce "enduring changes" in dopaminergic transmission or cellularity (Rogers et al. 1999). Chronic administration of morphine or heroin to rodents, however, causes decreased striatal concentrations of synaptic dopamine (Acquas et al. 1991; Crippens and Robinson 1994), its biosynthetic enzyme tyrosine hydroxylase (Self et al. 1995) and those of DAT (Simantov 1993). Chronic morphine appears to damage dopaminergic neurons as indicated by impaired axonal transport from the dopamine cell body area of the ventral tegmental area (VTA) to nucleus accumbens, decreased size of dopaminergic cell bodies, and by increased expression in VTA of a marker of injury, glial fibrillary acidic protein (Beitner-Johnson et al. 1992; 1993; Beitner-Johnson and Nestler 1993; Self et al. 1995; SklairTavron et al. 1996). As these animal data suggest that opiates might impair, reversibly or irreversibly, brain dopaminergic function in humans, we determined whether concentrations of biochemical markers of dopamine nerve terminal function and integrity are decreased in post mortem striatum (caudate, putamen, nucleus accumbens) of human chronic heroin users. The markers included dopamine itself, dopamine biosynthetic enzymes tyrosine hydroxylase and dopa decarboxylase, DAT, and the vesicular monoamine transporter (VMAT2). VMAT2 transports cytoplasmic monoamine neurotransmitters into vesicles and appears to be a stable marker of dopamine nerve terminal integrity in the dopamine-rich striatum (Vander Borght et al. 1995; Wilson and Kish 1996).

In addition, as changes in monoamine neurotransmitter metabolism have been described in animals (Gunne 1963) (cf. Wakabayashi et al. 1995), we measured levels of dopamine metabolites (homovanillic acid, 3-methoxytyramine, dihdroxyphenylacetic acid), serotonin and metabolite 5-hydroxyindoleacetic acid, and noradrenaline. Finally, as experimental animal data show that chronic opiate administration can upregulate striatal concentrations of extracellular signal-regulated kinases (ERKs), signaling molecules that may be involved in the regulation of levels of tyrosine hydroxylase (Ortiz et al. 1995; Berhow et al. 1996), we also determined striatal concentration of ERK2 in the heroin users. Our biochemical findings suggest that chronic heroin exposure might modestly decrease both dopaminergic and serotonergic function in the human.

\section{SUBJECTS AND METHODS}

Post mortem brain material from a total of 14 control subjects and nine users of heroin was obtained from medical examiner offices in the U.S.A. using a standardized protocol. The mean ages and post mortem time (interval between death and freezing of the brain) between the drug abuse and matched control groups did not differ significantly (controls: $34 \pm 4$ years; $14 \pm 2$ hours; heroin: $38 \pm 2$ years [ $p=.44$ ]; $13 \pm 2$ hours [ $p=$ .94]; mean \pm S.E., Student's two-tailed t-test). At autopsy, one half-brain was fixed in formalin fixative for neuropathological investigation whereas the other half was immediately frozen at $-80^{\circ} \mathrm{C}$ until biochemical analysis. Clinical information was obtained by the medical examiners using a questionnaire format and through structured telephone interviews with the next of kin. This study was approved by the Institutional Review Board of the University of Toronto.

\section{Control subjects for comparison with drug users}

Autopsied brain was obtained from 14 neurologically normal subjects who died from a variety of causes (trauma [four subjects], cardiovascular disease [seven subjects], leukemia [one subject], renal failure [one subject], and drowning [one subject]) who showed no abnormalities upon brain neuropathological analysis. All control subjects tested negative for drugs of abuse in blood, autopsied brain, and, in the ten cases for which hair was available, sequential one-half inch hair samples (see Kish et al. 1999).

\section{Drug users}

The subjects for the heroin group, previously reported (Kish et al. 1999), were selected from a large group of potential cases who met the following criteria: 1) presence of heroin metabolites (6-acetylmorphine, morphine, or morphine glucuronide) on toxicology screens in blood, autopsied brain, and, if available, as was the case in eight of the nine heroin users, scalp hair; 2) absence of other drugs of abuse in bodily fluids with the exception of ethanol; 3) evidence from the case records of primary use of heroin for at least one year prior to death; and 4) absence of neurological illness or, at autopsy, brain pathology unrelated to use of the drug. Most of the potential subjects were rejected because of a known history, confirmed by forensic drug examination, of significant use of cocaine. All of the heroin users administered the drug intravenously for a duration ranging from at least one year to 27 years. The pattern of recent drug use was daily (four subjects), two-three times a week (one subject) or unknown (four subjects). Five of the nine heroin users had been previously arrested for drug-related offenses. The suspected cause of death was acute narcotic intoxication (eight subjects) and atherosclerotic cardiovascular disease with acute narcotic intoxication as a contributing factor (one subject). Brain neuropathological analyses of the heroin us- 
ers disclosed no significant abnormalities in brain (including the substantia nigra and nucleus paranigralis brain areas) with the exception of mild ventricular dilatation (one subject) and mild diffuse gliosis in diencephalon and lower brain stem (one subject). Heroin and metabolite drug levels were measured by a gas chromatography/mass spectrometry procedure as previously described (Kish et al. 1999).

\section{Brain dissection and neurochemical analyses}

Brain regions were dissected using the atlas of Riley (Riley 1960) and, for the nucleus accumbens, as previously described (Hörtnagl et al. 1983). Levels of monoamine neurotransmitters and metabolites (HPLC with electrochemical detection; Wilson et al. 1994) and estimates of DAT (ten point $\left[{ }^{3} \mathrm{H}\right]$ WIN 35,428 filtration binding assay; Wilson et al. 1996c), VMAT2 by radioligand binding (ten point $\left[{ }^{3} \mathrm{H}\right]$ dihydrotetrabenazine filtration binding assay; Wilson et al. 1996c), tyrosine hydroxylase protein and dopa decarboxylase protein by quantitative blot immunolabeling (Ordway et al. 1994; Zhong et al. 1995), VMAT2 protein by quantitative blot immunolabeling using an affinity-purified antibody (Chemicon) raised against a previously described peptide (Erickson et al. 1996), and ERK1/2 protein by quantitative blot immunolabeling (Ortiz et al. 1995) were conducted as previously described.

\section{Statistical analyses}

Statistical comparisons between control and heroin groups values were conducted using the Student's twotailed t-test at the 0.05 criterion level.

\section{RESULTS}

\section{Monoamine neurotransmitters and metabolites}

As shown in Table 1, concentrations of dopamine and its metabolites homovanillic acid, dihydroxyphenylacetic acid, and 3-methoxytyramine were normal in the three striatal subdivisions of the heroin users with the exception of a statistically significant reduction (-33\%) in concentration of homovanillic acid in the nucleus accumbens. Statistically significant changes in striatal levels of noradrenaline and serotonin were limited to an increase $(+52 \%)$ in serotonin concentration in putamen of the heroin users. Striatal levels of the serotonin metabolite 5-hydroxyindoleacetic acid were decreased by $27-38 \%$ ( $p<.05$ for putamen and nucleus accumbens) in the heroin group.

\section{Tyrosine hydroxylase and dopa decarboxylase}

Mean protein concentrations of tyrosine hydroxylase were decreased significantly by $33 \%$ (caudate) and $25 \%$

Table 1. Concentrations of Monoamine Neurotransmitters and Metabolites, Dopamine Biosynthetic Enzymes (TH, DDC), Dopamine Transporter ( $\left[{ }^{3} \mathrm{H}\right]$ WIN 35,428 binding), the Vesicular Monoamine Transporter $\left(\left[{ }^{3} \mathrm{H}\right]\right.$ dihydrotetrabenazine Binding; VMAT2 Protein) and ERK in Postmortem Striatum of Control Subjects and of Heroin Users

\begin{tabular}{|c|c|c|c|c|c|c|c|c|c|}
\hline & \multicolumn{3}{|c|}{ Caudate } & \multicolumn{3}{|c|}{ Putamen } & \multicolumn{3}{|c|}{ Nucleus accumbens } \\
\hline & Controls & Heroin & $P$ value & Controls & Heroin & $P$ value & Controls & Heroin & P value \\
\hline Dopamine & $7.03 \pm 0.52$ & $6.34 \pm 0.44$ & .34 & $7.61 \pm 0.64$ & $6.81 \pm 0.50$ & .36 & $2.42 \pm 0.26$ & $1.65 \pm 0.41$ & .09 \\
\hline HVA & $6.78 \pm 0.69$ & $5.45 \pm 1.01$ & .25 & $10.34 \pm 0.93$ & $8.13 \pm 1.13$ & .13 & $5.80 \pm 0.47$ & $3.91 \pm 0.72^{*}$ & .03 \\
\hline DOPAC & $0.41 \pm 0.05$ & $0.33 \pm 0.09$ & .37 & $0.52 \pm 0.07$ & $0.35 \pm 0.09$ & .14 & $0.25 \pm 0.05$ & $0.20 \pm 0.05$ & .50 \\
\hline 3-MT & $1.99 \pm 0.17$ & $2.18 \pm 0.26$ & .49 & $2.51 \pm 0.20$ & $2.32 \pm 0.29$ & .58 & $1.78 \pm 0.13$ & $1.34 \pm 0.21$ & .06 \\
\hline NA & $0.15 \pm 0.04$ & $0.20 \pm 0.05$ & .37 & $0.14 \pm 0.02$ & $0.21 \pm 0.05$ & .14 & $1.39 \pm 0.30$ & $1.73 \pm 0.33$ & .45 \\
\hline Serotonin & $0.33 \pm 0.05$ & $0.39 \pm 0.09$ & .52 & $0.33 \pm 0.05$ & $0.50 \pm 0.07^{*}$ & .05 & $0.43 \pm 0.04$ & $0.45 \pm 0.08$ & .79 \\
\hline 5-HIAA & $0.63 \pm 0.09$ & $0.43 \pm 0.06$ & .10 & $0.93 \pm 0.08$ & $0.68 \pm 0.06^{*}$ & .03 & $0.92 \pm 0.11$ & $0.57 \pm 0.07^{*}$ & .02 \\
\hline $\mathrm{TH}$ protein & $1.19 \pm 0.14$ & $0.80 \pm 0.07^{*}$ & .03 & $0.86 \pm 0.05$ & $0.79 \pm 0.07$ & .38 & $1.10 \pm 0.09$ & $0.82 \pm 0.04^{*}$ & .01 \\
\hline DDC protein & $0.89 \pm 0.08$ & $0.77 \pm 0.07$ & .30 & $0.98 \pm 0.05$ & $1.01 \pm 0.05$ & .76 & $1.11 \pm 0.10$ & $0.99 \pm 0.06$ & .33 \\
\hline WIN-B ${ }_{\max }$ & $2.95 \pm 0.28$ & $2.61 \pm 0.22$ & .41 & $2.80 \pm 0.17$ & $2.63 \pm 0.14$ & .50 & $2.40 \pm 0.30$ & $1.81 \pm 0.27$ & .18 \\
\hline WIN-K ${ }_{d}$ & $7.8 \pm 0.5$ & $8.8 \pm 0.7$ & .30 & $9.1 \pm 0.8$ & $8.0 \pm 0.6$ & .34 & $12.7 \pm 1.2$ & $8.1 \pm 0.7^{*}$ & .01 \\
\hline TBZ-B ${ }_{\max }$ & $2.08 \pm 0.14$ & $2.03 \pm 0.14$ & .80 & $2.04 \pm 0.13$ & $2.25 \pm 0.10$ & .27 & $1.35 \pm 0.13$ & $1.27 \pm 0.20$ & .73 \\
\hline${\text { TBZ}-K_{d}}$ & $2.6 \pm 0.2$ & $3.8 \pm 0.2^{*}$ & .01 & $2.5 \pm 0.2$ & $4.7 \pm 0.2^{*}$ & .01 & $2.8 \pm 0.2$ & $4.1 \pm 0.5^{*}$ & .01 \\
\hline VMAT2 protein & $0.94 \pm 0.05$ & $0.85 \pm 0.06$ & .27 & $0.89 \pm 0.08$ & $0.98 \pm 0.09$ & .46 & $0.91 \pm 0.13$ & $0.62 \pm 0.04$ & .07 \\
\hline ERK protein & $0.97 \pm 0.06$ & $0.87 \pm 0.04$ & .19 & $1.20 \pm 0.05$ & $1.14 \pm 0.05$ & .42 & $0.85 \pm 0.08$ & $0.99 \pm 0.10$ & .29 \\
\hline
\end{tabular}

Values (monoamines, $\mathrm{ng} / \mathrm{mg}$ tissue; $\mathrm{B}_{\max }\left[\right.$ density], fmol/ $\mu \mathrm{g}$ protein; $\mathrm{K}_{\mathrm{d}}, \mathrm{nM} ; \mathrm{TH}, \mathrm{DDC}, \mathrm{VMAT2}$, and ERK protein, $\mu \mathrm{g}$ tissue standard/ $\mu \mathrm{g}$ protein) represent mean \pm S.E. of 10-14 control subjects and 8-9 heroin users. Abbreviations: HVA, homovanillic acid; DOPAC, dihydroxyphenylacetic acid; 3-MT, 3-methoxytyramine; NA, noradrenaline; 5-HIAA, 5-hydroxyindoleacetic acid; WIN, [ $\left.{ }^{3} \mathrm{H}\right] \mathrm{WIN} 35,428$ binding; TBZ, [ $\left.{ }^{3} \mathrm{H}\right]$ dihydrotetrabenazine binding; VMAT2, vesicular monoamine transporter; ERK extracellular signal-regulated protein kinase $2 .{ }^{*} p<.05$, Student's two-tailed t-test. 
(nucleus accumbens) in the heroin users whereas levels of dopa decarboxylase were normal in all three striatal subdivisions (Table 1 ).

\section{ERK}

Mean levels of ERK2 were normal in striatum of the heroin group (Table 1). Similar results were observed for ERK1 levels (data not shown).

\section{DAT and VMAT2}

No statistically significant differences from control levels were observed for binding density $\left(B_{\max }\right)$ of either $\left[{ }^{3} \mathrm{H}\right]$ WIN 35,428 , or $\left[{ }^{3} \mathrm{H}\right]$ dihydrotetrabenazine or VMAT2 protein in the heroin group (Table 1). The affinity constants $\left(\mathrm{K}_{\mathrm{d}}\right)$ for $\left[{ }^{3} \mathrm{H}\right]$ WIN 35,428 binding were decreased significantly by $36 \%$ in the nucleus accumbens and those for $\left[{ }^{3} \mathrm{H}\right]$ dihydrotetrabenazine increased by $46-88 \%$ in the three striatal subdivisions of the heroin users.

To establish whether there might be any relationship in the heroin users between the extent of recent exposure of heroin and the biochemical changes, a correlation analysis (Spearman Rank) was performed between levels of "total heroin" (the sum of "total morphine" [free morphine plus morphine glucuronide] and 6-acetyl morphine) measured in occipital cortex and the brain monoamine and transporter concentrations. Statistically significant correlations with drug levels were limited to caudate dopa decarboxylase protein (-0.80; $p=.02)$, putamen dopamine $(-0.71 ; p=.04)$ and noradrenaline $(0.73 ; p=.03)$, and nucleus accumbens $\left[{ }^{3} \mathrm{H}\right] \mathrm{di}-$ hydrotetrabenazine binding density $(-0.70 ; p=.04)$.

\section{DISCUSSION}

The major finding of our investigation is that striatal concentrations of several biochemical indices of dopamine and serotonin neurotransmitter activity are modestly reduced in brain of human heroin users.

\section{Dopamine levels, biosynthesis, and metabolism}

As most of striatal dopamine measured in post mortem human brain is intracellular, rather than synaptic, our finding of normal tissue concentrations of dopamine in the heroin users suggests that chronic heroin exposure, unlike that of methamphetamine (Wilson et al. 1996a), does not lead to substantial depletion of tissue stores of dopamine in humans. Nevertheless, we did observe a trend for a modest (by 32\%) dopamine reduction in the nucleus accumbens, with four of the nine heroin users having dopamine values below the lower limit of the control range in this brain area. We also found, in nucleus accumbens, decreased levels of the dopamine me- tabolite homovanillic acid (an index of dopamine "turnover"), and of protein concentration of tyrosine hydroxylase (the rate-limiting enzyme for dopamine biosynthesis). Taken together, these data suggest that dopaminergic activity might be modestly decreased in nucleus accumbens of chronic heroin users. This could occur as a compensatory response to prolonged dopaminergic stimulation by heroin (see also below). Our findings also support the possibility (Acquas et al. 1991; Crippens and Robinson 1994) that decreased dopaminergic function in nucleus accumbens might explain part of the dysphoria (e.g., anhedonic motivational state) associated with heroin withdrawal in humans.

\section{DAT}

Chronic exposure to cocaine can alter, by unknown mechanism, levels of striatal DAT independently of any change in number of dopamine neurons (cf. Wilson et al. 1994). In rats, nucleus accumbens DAT is decreased following chronic morphine administration (Simantov 1993). In our human study, however, we found no statistically significant change in striatal DAT levels. Nevertheless, we did find a slight trend for decreased (by $25 \%)$ DAT concentration in nucleus accumbens of the heroin users, suggesting that chronic heroin exposure might downregulate levels of the transporter in some users of the drug and thereby prolong the action of dopamine released into the synapse.

\section{ERK}

Animal data suggest that ERK might be involved in regulation by opiate drugs of tyrosine hydroxylase, with protein levels increased in rat "striatum" (the rodent counterpart of the human caudate and putamen) following chronic morphine administration (Ortiz et al. 1995; Berhow et al. 1996). Our data suggest, however, that any regulation by ERK of tyrosine hydroxylase in the human does not involve changes in actual striatal levels of ERK.

\section{Serotonin}

It has long been hypothesized that impulsive and risktaking behavior associated with decreased brain serotonergic function might increase vulnerability to substance abuse (Linnoila et al. 1983; McCown 1988). In the rat, lesion of serotonergic innervation to nucleus accumbens increases morphine self-administration (Smith et al. 1987) whereas activation of the serotonin system by dexfenfluramine suppresses heroin self-administration (Wang et al. 1995). In the human heroin users we did not find reduced levels of serotonin in striatum or, as was observed in our previous investigation of human methamphetamine users (Wilson et al. 1996a), in orbitofrontal 
cortex (Brodmann areas 11 and 12; data not shown). This suggests that heroin is not toxic to brain serotonin neurons and does not cause depletion of tissue stores of the neurotransmitter in human users of the drug. We did observe, however, decreased levels of the serotonin metabolite 5-hydroxyindoleacetic acid in striatum and in frontal (Brodmann areas 6, 10, 10 medial, 12), temporal (area 21 ), and cingulate (area 24) cortices (data not shown) of the heroin users. Animal studies suggest that opiates acutely enhance activity of brain serotonergic neurons innervating the basal forebrain, as indicated by increased levels of 5-hydroxyindoleacetic acid in striatal microdialysates (Wise et al. 1995; Enrico et al. 1998) and in "whole" tissue (Spampinato et al. 1985; Wakabayshi et al. 1995; Desole et al. 1996). Decreased concentration of 5-hydroxyindoleacetic in heroin users suggests that serotonergic activity might be below normal, perhaps as a compensatory phenomenon to prolonged serotonergic stimulation. As the brain serotonin system has been implicated in both affective state and impulse control (Soubrie 1986), impaired function of the brain serotonergic system, if sufficiently severe in some heroin users, might alter both mood during drug withdrawal and the likelihood of drug-taking behavior.

\section{Does heroin damage dopaminergic neurons?}

Experimental animal data suggest that chronic opiate exposure might damage brain dopaminergic neurons. The changes described in rats include decreased levels of neurofilament proteins and size of cell bodies in the VTA, reduced axoplasmic transport, elevated concentration of a marker of cell damage, glial fibrillary acidic protein, and decreased axoplasmic transport from VTA to nucleus accumbens (see Introduction). In our qualitative histopathological analysis, we found no signs of obvious cell damage or loss in dopamine cell body regions of the substantia nigra or of the nucleus paranigralis (the human counterpart of the rodent VTA) areas of the heroin users. A systematic quantitative morphometric examination, however, was not performed and it is possible that modest cell loss or shrinkage (e.g., by $25 \%$ ) could have occurred, especially in the paranigralis area, which would not have been detected in our investigation. As animal data suggest that striatal VMAT2 is a stable marker of dopamine nerve terminal integrity, our finding of normal VMAT2 levels suggests that long-term heroin exposure does not cause permanent loss of dopamine neurons. The observation, however, of decreased tyrosine hydroxylase protein in nucleus accumbens and caudate nucleus is consistent with the possibility that heroin might impair axoplasmic transport of the enzyme from cell body to nerve ending in human dopaminergic neurons. As mentioned above, however, it is equally plausible that the tyrosine hydroxylase reduction represents a compensatory down- regulation of dopamine biosynthesis consequent to prolonged dopaminergic stimulation by heroin. Taken together, our biochemical findings suggest that any dopaminergic toxicity (i.e., structural or biochemical) caused by chronic heroin in the human is probably slight. Although care was taken to exclude subjects who had used other drugs of abuse, co-abuse of drugs such as cocaine or nicotine by the heroin users of our study might have influenced the effects of heroin on the dopaminergic system. Although we do not have information on nicotine use, co-abuse of cocaine was not likely, as indicated by the lack of presence of any psychostimulant in sequential hair segments.

\section{CONCLUSION}

It is generally assumed that chronic opiate abuse does not cause substantial reversible or irreversible changes in brain monoaminerigc neurons in humans. For example, based upon this assumption, a neuropsychological investigation into consequences of methamphetamine on human cognition has employed a group of heroin users as a "drug control" group (Rogers et al. 1999). Although our post mortem findings do suggest that heroin exposure affects levels of monoaminergic neurotransmitter indices to a lesser extent than does exposure to the psychostimulant methamphetamine (Wilson et al. 1996a), modest decreases in several brain dopaminergic and serotonergic indices were observed that could potentially modify behavior in human users of the drug.

\section{ACKNOWLEDGMENTS}

This study was supported by U.S. NIH NIDA DA07185 to SJK and NIMH MH00967 and MH55208 to JWH.

\section{REFERENCES}

Acquas E, Carboni E, Di Chiara G (1991): Profound depression of mesolimbic dopamine release after morphine withdrawal in dependent rats. Eur J Pharmacol 193:133-134

Beitner-Johnson D, Guitart X, Nestler EJ (1992): Neurofilament proteins and the mesolimbic dopamine system: common regulation by chronic morphine and chronic cocaine in the rat ventral tegmental area. J Neurosci 12:2165-2176

Beitner-Johnson D, Guitart X, Nestler EJ (1993): Glial fibrillary acidic protein and the mesolimbic dopamine system: Regulation by chronic morphine and LewisFischer strain differences in the rat ventral tegmental area. J Neurochem 61:1766-1773

Beitner-Johnson D, Nestler EJ (1993): Chronic morphine impairs axoplasmic transport in the mesolimbic dopamine system of the rat brain. NeuroReport 5:57-60 
Berhow MT, Hiroi N, Nestler EJ (1996): Regulation of ERK (Extracellular Signal Regulated Kinase), part of the neurotrophin signal transduction cascade, in the rat mesolimbic dopamine system by chronic exposure to morphine or cocaine. J Neurosci 16:4707-4715

Crippens D, Robinson TE (1994): Withdrawal from morphine or amphetamine: different effects on dopamine in the ventral-medial striatum studied with microdialysis. Brain Res 650:56-62

Desole MS, Esposito G, Fresu L, Migheli R, Enrico P, Mura MA, De Natale G, Miele E, Miele M (1996): Effects of morphine treatment and withdrawal on striatal and limbic monoaminergic activity and ascorbic acid oxidation in the rat. Brain Res 723:154-161

Di Chiara G (1995): The role of dopamine in drug abuse viewed from the perspective of its role in motivation. Drug Alcohol Depend 38:95-137

Enrico P, Mura MA, Esposito G, Serra P, Migheli R, De Natale G, Desole MS, Miele M, Miele E (1998): Effect of naloxone on morphine-induced changes in striatal dopamine metabolism and glutamate, ascorbic acid and uric acid release in freely moving rats. Brain Res 797:94102

Erickson JD, Schafer MKH, Bonner TI, Eiden LE, Weihe E (1996): Distinct pharmacological properties and distribution in neurons and endocrine cells of two isoforms of the human vesicular monoamine transporter. Proc Natl Acad Sci USA 93:5166-5171

Gunne LH (1963): Catecholamines and 5-hydroxytryptamine in morphine tolerance and withdrawal. Acta Physiol Scand 58:1-19

Hörtnagl H, Schlögl E, Sperk G, Hornykiewicz O (1983): The topographical distribution of the monoaminergic innervation of the human brain. Prog Brain Res 58:269-274

Kish SJ, Kalasinsky K, Furukawa Y, Guttman M, Ang L, Adams V, Reiber G, Anthony RA, Anderson W, Smialek J, DiStefano L (1999): Brain choline acetyltransferase activity in chronic human users of cocaine, methamphetamine, and heroin. Mol Psychiat 4:26-32

Linnoila M, Virkkunen M, Stein M, Nuptial A, Ripon R, Goodwill FK (1983): Low cerebrospinal fluid 5-hydroxyindoleacetic acid differentiates impulsive from nonimpulsive violent behavior. Life Sci 33:2609-2614

McCown W (1988): Multi-impulsive personality disorder and multiple substance abuse: Evidence from members of self-help groups. Br J Addiction 83:431-432

Ordway GA, Smith KS, Haycock JW (1994): Elevated tyrosine hydroxylase in the locus coeruleus of suicide victims. J Neurochem 62:680-685

Ortiz J, Harris HW, Guitart X, Terwilliger RZ, Haycock JW, Nestler EJ (1995): Extracellular signal-regulated protein kinases (ERKs) and ERK kinase (MEK) in brain: Regional distribution and regulation by chronic morphine. J Neurosci 15:1285-1297

Riley HA (1960): An Atlas of the Basal Ganglia, Brain stem and Spinal Cord. Hafner, New York

Rogers RD, Everitt BJ, Baldacchino A, Blackshaw AJ, Swainson R, Wynne K, Baker NB, Hunter J, Carthy T, Booker E, London M, Deakin JFW, Sahakian BJ, Robbins TW (1999): Dissociable deficits in the decision-making cognition of chronic amphetamine abusers, opiate abusers, patients with focal damage to prefrontal cortex, and tryptophan-depleted normal volunteers: Evidence for monoaminergic mechanisms. Neuropsychopharmacol 20:322-339

Self DW, McClenahan AW, Beitner-Johnson D, Terwilliger RZ, Nestler EJ (1995): Biochemical adaptations in the mesolimbic dopamine system in response to heroin selfadministration. Synapse 21:312-318

Simantov R (1993): Chronic morphine alters dopamine transporter density in the rat brain: possible role in the mechanism of drug addiction. Neurosci Lett 163:121124

Sklair-Tavron L, Shi W-X, Lane SB, Harris HW, Bunney BS, Nestler EJ (1996): Chronic morphine induces visible changes in the morphology of mesolimbic dopamine neurons. Proc Natl Acad Sci (USA) 93:11202-11207

Smith JE, Shultz K, Co C, Goeders NE, Dworkin SI (1987): Effects of 5,7-dihydroxytryptamine lesions of the nucleus accumbens on rat intravenous morphine selfadministration. Pharm Biochem Behav 26:607-612

Soubrie P (1986): Reconciling the role of central serotonin neurons in human and animal behavior. Behav Brain Sci 9:319-364

Spampinato U, Esposito E, Romandini S, Samanin R (1985): Changes of serotonin and dopamine metabolism in various forebrain areas of rats injected with morphine either systemically or in the raphe nuclei dorsalis and medianis. Brain Res 328:89-95

Vander Borght T, Kilbourn M, Desmond T, Kuhl D, Frey K (1995): The vesicular monoamine transporter is not regulated by dopaminergic drug treatments. Eur J Pharmacol 294:577-83

Wakabayashi H, Tokuyama S, Ho IK (1995): Simultaneous measurement of biogenic amines and their metabolites in rat brain regions after acute administration of and abrupt withdrawal from butorphanol or morphine. Neurochem Res 20:1179-1185

Wang Y, Joharchi N, Fletcher PJ, Sellers EM, Higgins GA (1995): Further studies to examine the nature of dexfenfluramine-induced suppression of heroin self-administration. Psychopharmacol 120:134-141

Wilson JM, Nobrega JN, Carroll M, Niznik HB, Shannak K, Lac ST, Pristupa ZB, Dixon LM, Kish SJ (1994): Heterogeneous subregional binding patterns of ${ }^{3} \mathrm{H}$-WIN 35,428 and ${ }^{3} \mathrm{H}-\mathrm{GBR} 12,935$ are differentially regulated by chronic cocaine self-administration. J Neurosci 14:29662979

Wilson JM, Kish SJ (1996): The vesicular monoamine transporter, in contrast to the dopamine transporter, is not altered by chronic cocaine self-administration in the rat. J Neurosci 16:3507-3510

Wilson JM, Kalasinsky KS, Levey AI, Bergeron C, Reiber G, Anthony RM, Schmunk GA, Shannak K, Haycock JW, Kish SJ (1996a): Striatal dopamine nerve terminal markers in human, chronic methamphetamine users. Nature Med 2:699-703

Wilson JM, Levey AI, Bergeron C, Kalasinsky K, Ang L, Peretti F, Adams VI, Smialek J, Anderson WR, Shannak K, Deck J, Niznik HB, Kish SJ (1996b): Striatal dopamine, dopamine transporter, and vesicular monoamine transporter in chronic cocaine users. Ann Neurol 40:428-439 
Wilson JM, Levey AI, Rajput A, Ang L, Guttman M, Shannak K, Niznik HB, Hornykiewicz O, Pifl C, Kish SJ (1996c): Differential changes in neurochemical markers of striatal dopamine nerve terminals in idiopathic Parkinson's disease. Neurology 47:718-726

Wise RA, Leone P, Rivest R, Leeb K (1995): Elevations of nucleus accumbens dopamine and DOPAC levels dur- ing intravenous heroin self-administration. Synapse 21:140-148

Zhong XH, Haycock JW, Robitaille Y, Fratkin J, Kopin A, Shannak K, Hornykiewicz O, Kish SJ (1995): Striatal tyrosine hydroxylase and dopa decarboxylase protein in dominantly-inherited olivopontocerebellar atrophy and idiopathic Parkinson's disease. Movement Disorders 10:10-17 